http://dx.doi.org/10.1590/1678-7141

Arq. Bras. Med. Vet. Zootec., v.67, n.2, p.334-342, 2015

\title{
Identificação imuno-histoquímica de VEGF e IGF-1 em ovários de cadelas no anestro e estro
}

\author{
[Immunohistochemical identification of VEGF and IGF-1 in ovaries of \\ bitches on anestrus and estrus] \\ M.V.D. Almeida ${ }^{1}$, D.S. Castro ${ }^{1}$, L.C. Rial ${ }^{1}$, J.P. Lustosa ${ }^{1}$, A.L.F. Bicalho ${ }^{2}$, H.H. Ortega ${ }^{3}$, \\ N.R. Salvetti ${ }^{3}$, M.V. Caliari ${ }^{4}$, F.G. Vieira ${ }^{5}$, G.R. Valle ${ }^{5^{*}}$ \\ ${ }^{1}$ Aluna de graduação - Pontifícia Universidade Católica de Minas Gerais - Betim, MG \\ ${ }^{2}$ Clínica Veterinária São Francisco de Assis - Belo Horizonte, MG \\ ${ }^{3}$ Faculdad de Ciencias Veterinarias - Universidad Nacional del Litoral - Esperanza, Santa Fé, Argentina \\ ${ }^{4}$ Universidade Federal de Minas Gerais - Belo Horizonte, MG \\ ${ }^{5}$ Pontifícia Universidade Católica de Minas Gerais - Betim, MG
}

\begin{abstract}
RESUMO
Com o objetivo de verificar a presença de VEGF e IGF-1 nos ovários de cadelas, foram realizadas análises imuno-histoquímicas do estroma cortical; teca e granulosa de folículos secundários, terciários e terciários préovulatórios luteinizados; e ovócitos de folículos primários, secundários e terciários de ovários de cinco cadelas em anestro (Anest) e cinco em estro (Est). A identificação das fases do ciclo estral foi realizada por citologia vaginal associada a dosagem plasmática de progesterona. Os ovários foram submetidos a tratamento imunohistoquímico para identificação de VEGF (anticorpo primário PU 360-UP, Biogenex, USA; diluição 1:30) e IGF-1 (anticorpo primário PabCa, Gro-Pep, Austrália; diluição 1:100). Determinou-se um índice de imunomarcação (IM), para cada tecido avaliado, pela razão entre a área positivamente marcada dividida pela área total analisada. Para os ovócitos, verificou-se imunomarcação positiva ou negativa. As comparações de IM entre tecidos foram realizadas pelo teste de Wilcoxon (diferentes tecidos em mesmo grupo) ou Mann-Whitney (mesmo tecido entre diferentes grupos), todas no nível de 5\% de significância. VEGF e IGF-1 foram identificados, de forma semelhante $(\mathrm{P}>0,05)$, em todas as estruturas avaliadas em ambos os grupos experimentais. Conclui-se que esses fatores de crescimento estão presentes em cadelas no anestro e estro, no estroma cortical ovariano, folículos em diferentes estádios de desenvolvimento e ovócitos.
\end{abstract}

Palavras-chave: cadela, ovário, ovócito, VEGF, IGF-1

\begin{abstract}
In order to verify the presence of VEGF and IGF-1 in the ovaries of bitches, immunohistochemical analyzes of the cortical stroma; theca and granulosa of secondary, tertiary and tertiary luteinized preovulatory follicles; and oocytes of primary, secondary and tertiary follicles of ovaries from five bitches in anestrous (Anest) and five in estrus (Est) was performed. The identification of the phases of the estrous cycle was performed by vaginal cytology associated with the measurement of plasma progesterone. The ovaries were treated for immunohistochemical identification of VEGF (PU 360 primary antibody-UP, Biogenex, USA, dilution 1:30) and IGF-1 (primary antibody PabCa, Gro-Pep, Australia; 1:100 dilution). The immunostaining index (MI) was determined for each tissue by the ratio of positively marked area divided by total analyzed area. For oocytes immunostaining was determined as positive or negative. Comparisons of IM between tissues were performed with the Wilcoxon test (deferent tissues in the same group) or Mann-Whitney test (same tissue between different groups), all at 5\% significance level. VEGF and IGF-1 have been similarly identified $(P>0.05)$ in all structures evaluated in both groups. It is concluded that in bitches in estrus and anestrous these growth factors are present in ovary cortical stroma, follicles at different stages of development and oocytes.
\end{abstract}

Keywords: bitch, ovary, oocyte, VEGF, IGF-1

Recebido em 16 de agosto de 2013

Aceito em 21 de agosto de 2014

*Autor para correspondência (corresponding author)

E-mail: guilhermerv@pucminas.br 


\section{INTRODUÇÃO}

A cadela, de forma semelhante a outras espécies, tem um padrão cíclico de crescimento folicular e ovulação determinado por interações hormonais do eixo hipotalâmico-hipofisário-gonadal. Entretanto, possui particularidades no ciclo estral que a diferem de outras fêmeas, dentre elas a ovulação de ovócitos primários, cuja maturação final ocorre nas tubas uterinas; luteinização préovulatória dos folículos terciários; e manutenção de corpos lúteos ativos mesmo que não ocorra gestação (Johnston et al., 2001). A razão para tais particularidades, mesmo estando envolvidos hormônios semelhantes aos de outros mamíferos, é motivo de estudos.

Nos mamíferos em geral, em seus estádios iniciais, a foliculogênese parece ser coordenada por fatores de crescimento (FCs) produzidos pelo próprio tecido ovariano ou outros tecidos, sendo as gonadotrofinas hipofisárias necessárias apenas nos estádios finais da foliculogênese, ovulação e formação do corpo lúteo, embora ainda participem FCs nestes últimos processos (Rajkovic et al., 2006; Stouffer, 2006; ChastantMaillard et al., 2011). Dentre os FCs envolvidos, estão o endotélio vascular (VEGF) e o semelhante à insulina 1 (IGF-1) (HernandezMedrano et al., 2012).

Embora sua participação esteja evidenciada em diversas espécies, como seres humanos (Rajkovic et al., 2006; Lee et al., 2012), murinos (Rajkovic et al., 2006), ruminantes (Rajkovic et al., 2006; Velazquez et al., 2008), equinos (Müller et al., 2009; Pereira et al., 2013) e suínos (Shimizu et al., 2003; Oberlender et al., 2013), há poucos relatos em cães (Chastant-Maillard et al., 2011). Estudos indicam a presença de VEGF no corpo lúteo de cadelas no diestro e anestro inicial (Mariani et al., 2006) e a presença de IGF-1 no fluido folicular de cadelas (Reynaud et al., 2010), bem como a participação deles na maturação in vitro de ovócitos caninos (Machado et al., 2007; Oliveira et al., 2009; ChastantMaillard et al., 2011).

O VEGF é um fator angiogênico ovariano (Fraser, 2006) presente no estroma cortical que proporciona suporte nutricional aos folículos primordiais e primários (Shin et al., 2005). Produzido por células da teca e granulosa de folículos antrais (Kaczmarek et al., 2005), participa na determinação de dominância folicular (Plendl, 2000; Ortega et al., 2007) e ovulação (Stouffer, 2006). Produzido por células lúteas (Mariani et al., 2006), participa na formação, desenvolvimento e atividade do corpo lúteo (Plendl, 2000; Fraser, 2006).

Os componentes da superfamília de FCs semelhantes à insulina (IGFs) compõem um sistema essencial nos mecanismos intraovarianos envolvidos na regulação do crescimento folicular e função do corpo lúteo, interagindo sinergicamente com as gonadotrofinas hipofisárias na regulação da proliferação e diferenciação de células da teca e granulosa folicular, resultando em proliferação das células da granulosa e estímulo à esteroidogênese, bem como crescimento do ovócito (Armstrong et al., 2002; Hernandez-Medrano et al., 2012). Apesar de a maior parte do IGF-1 ser produzida pelo fígado, atingindo seus órgãos alvo por via endócrina (Velazquez et al., 2008), é também produzido nos ovários, especialmente nas células da teca e granulosa de folículos terciários (Armstrong et al., 2002).

Ovócitos de diversas espécies também produzem FCs (Mermillod et al., 2006), dentre eles IGF-1 (Vendola et al., 1999; Satrapa et al., 2013). Entretanto, na cadela, apenas o FC de fibroblastos (FGF) (Songsasen et al., 2009) foi identificado até o momento. $\mathrm{Na}$ literatura consultada não foi encontrada menção à identificação de VEGF em ovócitos de nenhum mamífero.

Diante da escassez de informações sobre a participação de VEGF e IGF-1 na fisiologia ovariana de cadelas, este estudo teve o propósito de avaliar a presença desses FCs no estroma cortical, folículos ovarianos e ovócitos de cadelas em anestro e estro.

\section{MATERIAL E MÉTODOS}

Foram obtidos os ovários de cinco cadelas em anestro e cinco em estro, oriundos de animais submetidos a ovariossalpingo histerectomia (OSH) eletiva. A identificação da fase cíclica das cadelas foi realizada conforme Valle e Fóscolo (2012). Cadelas em anestro (grupo Anest) foram assim identificadas por meio de citologia vaginal com predomínio de células parabasais e intermediárias associada à dosagem de 
progesterona sérica menor que $1,0 \mathrm{ng} / \mathrm{mL}$ em animais previamente selecionados pela ausência de sinais clínicos de cio. Já as cadelas em estro (grupo Est) foram inicialmente identificadas pelos sinais clínicos de cio associados à citologia vaginal com predomínio de células superficiais, sendo submetidas à OSH quando a dosagem de progesterona estivesse entre 1,0 e $4,0 \mathrm{ng} / \mathrm{mL}$, indicando estro em fase pré-ovulatória.

As citologias vaginais foram realizadas por meio de introdução de um swab de algodão através da vulva, chegando à porção caudal da vagina, e fricção delicada. Em seguida, confeccionavam-se esfregaços em lâminas de microscopia, corava-se pelo método de Giemsa e avaliava-se em microscopia óptica sob aumento de 400X. As dosagens de progesterona sérica foram realizadas em soro obtido de sangue venoso pelo método de quimioluminescência.

Um dos ovários de cada cadela, aleatoriamente escolhido, foi fixado em formalina tamponada a $10 \%$ por 24 horas e armazenado em álcool etílico a $70^{\circ} \mathrm{GL}$. Em seguida, realizou-se a inclusão em parafina histológica e os blocos foram microtomizados a $3 \mu \mathrm{m}$, sendo confeccionadas lâminas para imunomarcação de VEGF e IGF-1, utilizando-se a mesma metodologia descrita por Ortega et al. $(2007 ; 2008)$.

Os cortes histológicos foram desparafinados, hidratados e pré-tratados em forno de microondas para recuperação antigênica. Em seguida, a atividade da peroxidase endógena foi inibida com $\mathrm{H}_{2} \mathrm{O}_{2}$ a $1 \%$ e realizado o bloqueio de ligações não específicas com soro normal de cabra a $10 \%$. Os cortes foram incubados com os anticorpos primários policlonais anti-VEGF (PU 360-UP, Biogenex, USA; diluição 1:30) ou anti-IGF-1 (PabCa, Gro-Pep, Austrália; diluição $1: 100$ ) a $4^{\circ} \mathrm{C}$, por 18 horas, e em seguida incubados à temperatura ambiente por 30 minutos com anticorpos secundários biotinizados de rato. A visualização dos antígenos foi realizada pelo método da streptoavidinaperoxidase e utilização de cromógeno 3,3-diaminoenzidina (DAB). Finalmente, as lâminas foram lavadas em água destilada, coradas com hematoxilina, desidratadas e montadas. Como controle da reação, lâminas de cada ovário foram submetidas ao procedimento anterior, porém com substituição do anticorpo primário por soro normal de coelho.

A classificação dos folículos quanto ao seu estádio de desenvolvimento foi realizada segundo Johnston et al. (2001) e Rajkovic et al. (2006). Para a correta identificação dos tipos foliculares, considerou-se: folículo primordial, aquele com ovócito, sem zona pelúcida, circundado por camada única de células pavimentosas; folículo primário, aquele com ovócito apresentando zona pelúcida e envolto por camada única de células cúbicas ou colunares; folículo secundário, aquele que apresentasse no seu interior ovócito com zona pelúcida e envolto por mais de uma camada de células da granulosa, sem antro folicular; folículo terciário, aquele com mais de uma camada de células da granulosa e antro presente, porém sem necessariamente ser visualizado ovócito; e folículo pré-ovulatório, aquele que apresentasse a camada granulosa em processo de luteinização e presença de antro, sem necessariamente ser visualizado ovócito. Aqueles folículos que apresentavam mais de uma camada de células da granulosa, porém sem visualização de ovócito e antro, foram classificados como folículo secundário/terciário.

A imunomarcação do estroma cortical ovariano foi avaliada em áreas nas quais não se verificava a presença de corpos lúteos ou folículos em nenhum estágio de desenvolvimento. Também se avaliou a teca e granulosa de folículos secundários e terciários e a teca e granulosa luteinizada de folículos pré-ovulatórios. As tecas interna e externa foram analisadas em conjunto, delimitadas por uma faixa de $20 \mu \mathrm{m}$ a partir da lâmina própria da camada granulosa. Já a camada granulosa foi delimitada externamente por sua lâmina própria e internamente pelos limites do antro, se presente. Havendo ovócito, ele era excluído da análise. Folículos primordiais não foram incluídos na avaliação de IM.

A metodologia empregada para captura, definição das condições de morfometria e obtenção das medidas foi a descrita por Costa et al. (2010). Realizando-se varredura de todo o tecido cortical ovariano disponível em cada lâmina, as estruturas desejadas foram visualizadas com aumento de $400 \mathrm{X}$ e digitalizadas, procurando-se obter o máximo de imagens através da microcâmera JVC TK- 
1270/RGB (JVC, Japão). De cada imagem foi obtida a área de imunomarcação positiva e a área total analisada, a fim de se obter um índice de imunomarcação (IM), estabelecido pela razão entre a área positivamente marcada dividida pela área total analisada.

As regiões desejadas foram individualmente delimitadas com o auxílio de um cursor para obtenção automática de sua área marcada por anticorpos anti-VEGF ou anti-IGF-1 em micrômetros quadrados $\left(\mu \mathrm{m}^{2}\right)$. As áreas positivas foram obtidas através da seleção de pixels da marcação imuno-histoquímica e criação de uma imagem binária, enquanto a área total avaliada foi calculada através da seleção de todos os pixels das áreas positivas e negativas. Todas as medidas foram obtidas pelo software KS300 contido no analisador de imagens Carl Zeiss (Carl Zeiss, Alemanha).

Para a avaliação da positividade ou não de imunomarcação de ovócitos, o citoplasma e/ou núcleo foram avaliados por microscopia óptica em aumento de 400X, sendo a imunomarcação considerada apenas como positiva ou negativa. Os ovócitos foram agrupados de acordo com o estádio de desenvolvimento do folículo a que pertenciam.

As comparações de IM entre tecidos foram realizadas pelo teste de Wilcoxon (deferentes tecidos em mesmo grupo) ou Mann-Whitney (mesmo tecido entre diferentes grupos). Considerou-se, em todos os casos, o nível de significância de $5 \%(\mathrm{P}<0,05)$.

A execução deste trabalho foi aprovada pelo Comitê de Ética em Experimentação Animal da UFMG, protocolo $n^{\circ}$ 176/2007, e pela Comissão de Ética no Uso de Animais da PUC Minas, protocolo $n^{\circ} 012 / 2009$.

\section{RESULTADOS}

A metodologia adotada para identificação inequívoca do estádio de desenvolvimento de cada folículo, a fim de não haver erros de interpretação de resultados, fez com que, em alguns cortes histológicos, nenhum folículo classificado como secundário fosse identificado. Tal situação fez com que a amostra ficasse reduzida para essa categoria folicular nos grupos, não permitindo comparações confiáveis. Situação semelhante ocorreu para folículos terciários no grupo Anest. Nessas situações, os dados de IM não foram incluídos nas tabelas de resultados. Entretanto, nos ovários de ambos os grupos em que foram encontrados folículos secundários e terciários, estes apresentavam imunomarcação positiva da teca e granulosa para VEGF e IGF-1. Ao ser considerada a categoria de folículo secundário/terciário, todos os animais puderam ser incluídos nas análises, em ambos os grupos experimentais. Não houve folículos préovulatórios para análise no grupo Anest, devido à própria condição dessa fase do ciclo estral.

Folículos primordiais e primários não foram incluídos na avaliação de IM devido à pequena área de avaliação que proporcionaram suas paredes foliculares. Entretanto, nos folículos primários, houve imunomarcação positiva, tanto para VEGF quanto para IGF-1, em ambos os grupos experimentais.

Os resultados obtidos na imunomarcação de VEGF (Tab. 1) e IGF-1 (Tab. 2) nos ovários dos diferentes grupos experimentais foram semelhantes, não sendo identificadas diferenças entre estruturas de um mesmo grupo experimental, ou entre diferentes grupos experimentais para uma mesma estrutura. A comparação entre diferentes folículos foi realizada apenas no grupo Est, não se observando diferença no IM entre folículo secundário/terciário e folículo pré-ovulatório (P>0,05), tanto para células da granulosa quanto para células da teca. Já na comparação entre grupos Anest e Est, folículos secundários/terciários apresentaram IMs semelhantes, tanto na granulosa quanto na teca $(\mathrm{P}>0,05)$. Os IMs do estroma cortical foram, também, semelhantes entre os grupos Anest e Est $(\mathrm{P}>0,05)$. Com relação à imunomarcação de ovócitos, todos os ovócitos (100\%) de todos os estádios foliculares avaliados, em ambos os grupos experimentais, tiveram marcação positiva, tanto para VEGF quanto para IGF-1.

A Figura 1 ilustra a imunomarcação de VEGF e IGF-1 nas diversas estruturas ovarianas de cadelas de ambos os grupos experimentais. 
Tabela 1. Índice de imunomarcação (IM; razão entre área marcada e área total) nas estruturas ovarianas (mediana) e percentual de ovócitos imunomarcados para VEGF em ovários de cadelas em anestro (Anest) e estro (Est)

\begin{tabular}{|c|c|c|c|}
\hline \multirow{2}{*}{\multicolumn{2}{|c|}{ Estrutura ovariana }} & \multicolumn{2}{|c|}{ Grupo experimental } \\
\hline & & Anest & Est \\
\hline \multirow{3}{*}{ Granulosa (mediana) } & Fol. pré-ovulatório & - & 0,19 \\
\hline & Fol. terciário & $\therefore$ & 0,09 \\
\hline & Fol. secundário/terciário & 0,12 & 0,20 \\
\hline \multirow{3}{*}{ Teca (mediana) } & Fol. pré-ovulatório & - & 0,07 \\
\hline & Fol. terciário & - & 0,06 \\
\hline & Fol. secundário/terciário & 0,14 & 0,07 \\
\hline \multicolumn{2}{|l|}{ Estroma (mediana) } & 0,33 & 0,29 \\
\hline \multirow{5}{*}{ Ovócitos (\%) } & Fol. terciário & $2 / 2(100)$ & $5 / 5(100)$ \\
\hline & Fol. secundário & $56 / 56(100)$ & $14 / 14(100)$ \\
\hline & Fol. primário & $19 / 19(100)$ & $62 / 62(100)$ \\
\hline & Fol.primordial & $52 / 52(100)$ & $57 / 57(100)$ \\
\hline & Todos os folículos & $129 / 129(100)$ & $138 / 138(100)$ \\
\hline
\end{tabular}

Tabela 2. Índice de imunomarcação (IM; razão entre área marcada e área total) nas estruturas ovarianas (mediana) e percentual de ovócitos imunomarcados para IGF-1 em ovários de cadelas em anestro (Anest) e estro (Est)

\begin{tabular}{|c|c|c|c|}
\hline \multirow{2}{*}{\multicolumn{2}{|c|}{ Estrutura ovariana }} & \multicolumn{2}{|c|}{ Grupo experimental } \\
\hline & & Anest & Est \\
\hline \multirow{3}{*}{ Granulosa (mediana) } & Fol. pré-ovulatório & - & 0,15 \\
\hline & Fol. terciário & - & 0,21 \\
\hline & Fol. secundário/terciário & 0,29 & 0,22 \\
\hline \multirow{3}{*}{ Teca (mediana) } & Fol. pré-ovulatório & - & 0,15 \\
\hline & Fol. terciário & - & 0,16 \\
\hline & Fol. secundário/terciário & 0,25 & 0,18 \\
\hline Estroma (mediana) & & 0,20 & 0,23 \\
\hline \multirow{5}{*}{ Ovócitos (\%) } & Fol. terciário & $12 / 12(100)$ & $8 / 8(100)$ \\
\hline & Fol. secundário & $133 / 133(100)$ & $33 / 33(100)$ \\
\hline & Fol. primário & $64 / 64(100)$ & $59 / 59(100)$ \\
\hline & Fol. primordial & $145 / 145(100)$ & $62 / 62(100)$ \\
\hline & Todos os folículos & $354 / 354(100)$ & $162 / 162(100)$ \\
\hline
\end{tabular}

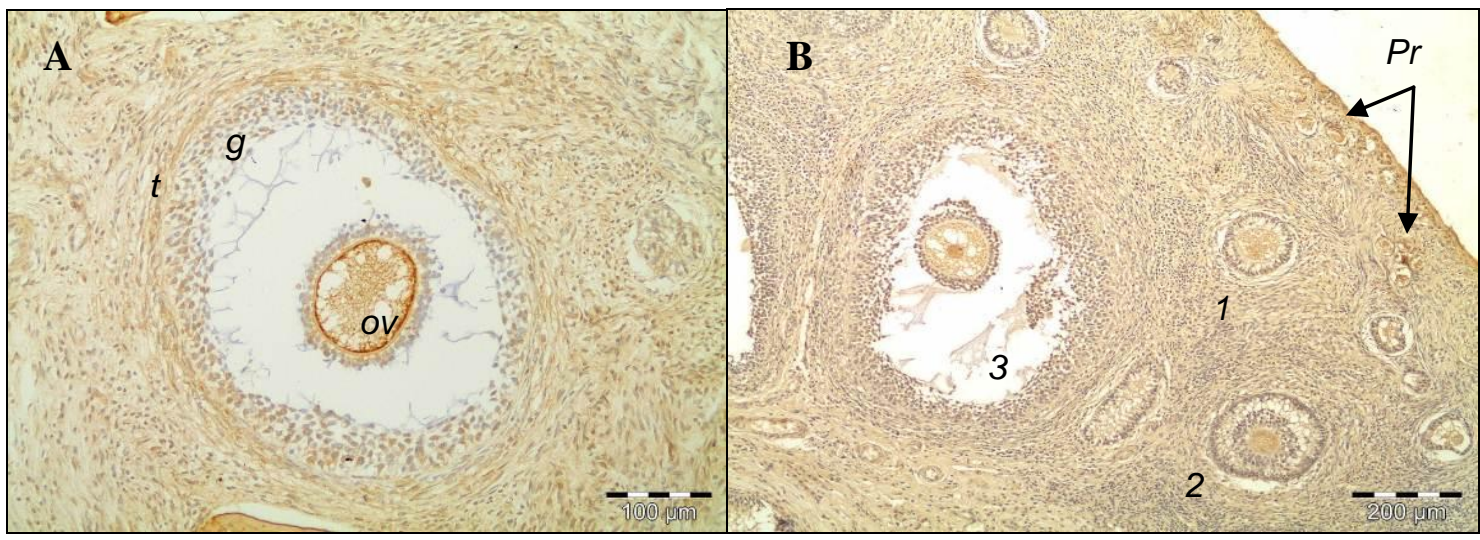

Figura 1. Estruturas ovarianas imunomarcadas (coloração parda) para VEGF e IGF-1 em ovários de cadelas. A) imunomarcação de VEGF em folículo terciário ( $t$, teca; $g$, granulosa; ov, ovócito) (Anestro, 200X); B) imunomarcação de IGF-1 em folículos primordiais (Pr), primário (1), secundário (2) e terciário (3) (Anestro, 100X). 


\section{DISCUSSÃO}

Foi evidenciada a presença de VEGF e IGF-1 em toda a região cortical dos ovários de cadelas, envolvendo o estroma, os diferentes componentes dos diversos tipos foliculares, tanto em animais em anestro quanto em estro. Entretanto, não foram evidenciadas diferentes intensidades de imunomarcação entre as estruturas avaliadas, tanto no anestro como no estro; assim como intensidades de imunomarcação semelhantes nas diversas estruturas avaliadas na comparação entre anestro e estro. Esses achados mostram que, na cadela, de forma semelhante ao que ocorre em outras espécies (Shimizu et al., 2003; Rajkovic et al., 2006; Velazquez et al., 2008; Müller et al., 2009; Hernandez-Medrano et al., 2012; Lee et al., 2012; Oberlender et al., 2013; Pereira et al., 2013), VEGF e IGF-1 possivelmente tenham participação na dinâmica folicular e formação do corpo lúteo. Entretanto, não parece haver concentração diferenciada desses FCs entre anestro e estro, pelo menos para as estruturas avaliadas neste experimento.

O VEGF e IGF-1 mostraram-se presentes no estroma cortical dos ovários das cadelas, assim como relatado por Shin et al. (2005) para VEGF em murinos. A presença de IGF-1 no estroma cortical não significa, necessariamente, que esse FC tenha sido ali produzido, já que a maior parte do IGF-1 que atua nos tecidos é produzida pelo fígado, atingindo seus órgãos alvo por via endócrina (Velazquez et al., 2008). Entretanto, o mesmo não é relatado para VEGF, o que permite afirmar que ele é produzido pelo ovário de cadelas, tanto no anestro quanto no estro, pelo estroma cortical e teca e granulosa dos diversos estádios de desenvolvimento folicular. Já IGF-1, apesar de estar presente nas mesmas estruturas, pode não ser, necessariamente, produzido localmente.

VEGF e IGF-1 mostraram-se presentes não apenas nas células da teca e granulosa de folículos antrais, mas ainda de folículos préantrais primários e secundários, possivelmente tendo também alguma ação sobre esses folículos. Songsasen et al. (2009) chegaram a conclusão semelhante quanto à participação dos FCs fibroblástico 2 (FGF-2) e 7 (FGF-7) ao identificá-los nos ovários de cadelas.
Em folículos antrais, a ação angiogênica de VEGF lhe confere participação direta na determinação de dominância folicular (Plendl, 2000; Kaczmarek et al., 2005; Ortega et al., 2007) e ovulação (Stouffer, 2006), tendo também ação indireta ao estimular a atividade de IGF-1 (Lee et al., 2012). IGF-1 age sinergicamente com as gonadotrofinas hipofisárias, o que lhe confere participação na proliferação celular da granulosa e esteroidogênese das células da teca e granulosa (Hernandez-Medrano et al., 2012). Isso possivelmente ocorre também em cães (Reynaud et al., 2010), mas não há menção às suas ações em folículos pré-antrais nessa espécie.

VEGF foi anteriormente identificado em células de folículos primordiais e primários de várias espécies (Plendl, 2000), mas não de cadelas. Grande crescimento do ovócito de cadelas ocorre na transição entre os estádios foliculares de primordial para primário, e em seguida para secundário (Songsasen et al., 2009), e esses FCs presentes no estroma e nas células de folículos primários e secundários podem ter participação nisso nas cadelas. Componentes da superfamília de IGFs têm estabelecida sua participação no crescimento e maturação do ovócito em suas fases finais de desenvolvimento em diversas espécies (Armstrong et al., 2002), mas não ainda identificada a participação nas suas fases iniciais.

Ovócitos também produzem FCs que regulam o desenvolvimento de folículos pré-antrais e antrais (Mermillod et al., 2006), dentre eles IGF1 (Vendola et al., 1999), mas VEGF não é citado como um desses FCs. Até o momento, apenas FGF-2 e FGF-7 foram identificados em ovócitos de folículos primordiais, primários e secundários nas diversas fases cíclicas de cadelas, exceto no anestro (Songsasen et al., 2009). A presença de VEGF e IGF-1 em ovócitos nas suas diversas fases de desenvolvimento, tanto no anestro quanto no estro de cadelas, não havia ainda sido relatada na literatura.

Por ter atividade angiogênica (Redmer e Reynolds, 1996), possivelmente VEGF não tenha nenhuma ação direta sobre o desenvolvimento dos ovócitos, mas pode ter sobre as células foliculares. FGF-2 e FGF-7, também angiogênicos, foram identificados nos ovócitos de cadelas (Songsasen et al., 2009), mas nenhuma menção sobre funções diretas sobre o próprio ovócito ou células foliculares foi feita 
pelos autores. Já o IGF-1 pode ter ação direta sobre os ovócitos no seu desenvolvimento final (Rajkovic et al., 2006; Pereira et al., 2013) e/ou sobre as células foliculares (Vendola et al., 1999). A utilização de FCs na maturação in vitro de ovócitos se baseia em suas prováveis atividades in vivo (Farsi et al., 2013), e dentre eles estão VEGF (Kere et al., 2014) e IGF-1 (Oberlender et al., 2013; Meiyu et al., 2014), este último também utilizado em meios de cultivo de ovócitos caninos (Rodrigues e Rodrigues, 2003; Chastant-Maillard et al., 2011). Entretanto, ainda não se consegue eficiente maturação in vitro de ovócitos caninos (Chastant-Maillard et al., 2011).

Redmer e Reynolds (1996) afirmam que FCs angiogênicos são produzidos por corpos lúteos nas suas diversas fases de desenvolvimento. Mariani et al. (2006) demonstraram a presença de VEGF no corpo lúteo de cadelas no diestro e início do anestro, onde participaria modulando a atividade das células luteínicas, de forma semelhante ao que ocorre em outras espécies (Plendl, 2000; Fraser, 2006). A presença de VEGF nos folículos pré-ovulatórios luteinizados das cadelas evidencia que esse FC é produzido por células da granulosa luteinizadas de cadelas de forma semelhante ao que ocorre em mulheres (Engmann et al., 2011), e deve ter participação não apenas na atividade do corpo lúteo do diestro, mas também na luteinização préovulatória do folículo terciário das cadelas durante o estro. Ao se transformar em tecido luteínico, a camada granulosa do folículo é invadida por vasos sanguíneos derivados da teca interna (Stouffer, 2006), e esse processo conta com a participação do VEGF (Redmer e Reynolds, 1996).

A participação de IGF-1, em sinergismo com o hormônio luteinizante ( $\mathrm{LH})$, no desenvolvimento e esteroidogênese das células luteínicas, foi evidenciada em diversas espécies (Stouffer, 2006), bem como sua ação modulando a atividade de VEGF (Martinez-Chequer et al., 2003). Entretanto, não foi encontrada menção dessa mesma atividade em cadelas, mas a presença de IGF-1 nas células da granulosa luteinizadas de folículos terciários de cadelas sugere essa mesma atividade em cães.

\section{CONCLUSÃO}

Em ovários de cadelas no anestro e estro, VEGF e IGF-1 estão presentes no estroma cortical, na teca, granulosa e ovócitos de folículos primários, secundários, terciários e pré-ovulatórios luteinizados, bem como em ovócitos de folículos primordiais.

\section{AGRADECIMENTOS}

Este experimento contou com apoio financeiro da FAPEMIG, Probic PUC Minas (2665/2008 e 6006/2011) e Fip PUC Minas (4809-2S/2009).

\section{REFERÊNCIAS}

ARMSTRONG, D.G.; BAXTER, G; HOGG, C.O. et al. Insulin-like growth factor (IGF) system in the oocyte and somatic cells of bovine preantral follicles. Reproduction, v.123, p.789-797, 2002.

CHASTANT-MAILLARD, S.; LESEGNO, C.V.; CHEBROUT, M. et al. The canine oocyte: uncommon features od in vivo and in vitro maturation. Reprod. Fertil. Devel., v.23, p.391-402, 2011.

COSTA, C.A.; NUNES, A.C.; FERREIRA, A.J. et al. Entamoeba histolytica and E. dispar trophozoites in the liver of hamsters: in vivo binding of antibodies and complement. Parasit. Vectors, v.26, p.23, 2010.

ENGMANN, L.; ROMAK, J.; NULSEN, J. et al. In vitro viability and secretory capacity of human luteinized granulosa cells after gonadotropin-releasing hormone agonist trigger of oocyte maturation. Fertil. Steril., v.96, p.198-202, 2011.

FARSI, M.M.; KAMALI, N.; POURGHASEM, M. Embryological aspects of oocyte in vitro maturation. Int. J. Mol. Cell Med., v.2, p.99-109, 2013.

FRASER, H.M. Regulation of the ovarian follicular vasculature. Reprod. Biol. Endocrinol., v.4, p.18, 2006

HERNANDEZ-MEDRANO, J.H.; CAMPBELL, B.K.; WEBB, R. Nutritional influences on folliculogenesis. Reprod. Dom. Anim., Suppl.4, v.47, p.274-282, 2012.

JOHNSTON, S.D.; KUSTRITZ, M.V.R.; OLSON, P.N.S. The canine estrous cycle. In: __ Canine and feline theriogenology. Philadelphia: W.B. Saunders, 2001. p.16-31.

KACZMAREK, M.M.; SCHAMS, D.; ZIECIK, A.J. Role of vascular endothelial growth factor in ovarian physiology - an overview. Reprod. Biol., v.5, p.111$136,2005$. 
KERE, M.; SIRIBOON, C.; LIAO, J.W. et al. Vascular endothelial growth factor A improves quality of matured porcine oocytes and developing partenotes. Domest. Anim. Endocrinol., v.49, p.60-69, 2014.

LEE, S-R.; KIM, S-H.; CHAE, H-D. et al. Influence of vascular endothelial growth factor on the expression of insulin-like growth factor-II, insulin-like growth factor binding protein-2 and 5 in human luteinized granulosa cells. Gynecol. Endocrinol., v.28, p.917920, 2012.

MACHADO, M.A.; TONIOLLO, G.H.; OLIVEIRA, $\mathrm{K}$. Influência do fator de crescimento semelhante à insulina I (IGF-I) adicionado ao meio fluido sintético de tuba uterina (SOF) sobre a maturação in vitro de oócitos caninos (Canis familiaris). Semina Cienc. Agrar., v.28, p.455-464, 2007.

MARIANI, T.C.; PRADO, C.; SILVA, L.G. et al. Immunohistochemical localization of VEGF and its receptors in the corpus luteum of the bitch during diestrus and anestrus. Theriogenology, v.66, p.17151720, 2006.

MARTINEZ-CHEQUER, J.C.; STOUFFER, R.L.; HAZZARD, T.M. et al. Insulin-like growth factor (IGF)-1 and -2, but not hypoxia, synergize with gonadotropin hormone to promote vascular endothelial growth factor (VEGF)-A secretion by monkey granulosa cells from preovulatory follicles. Biol. Reprod., v.68, p.1112-1118, 2003.

MEIYU, Q.; LIU, D.; ROTH, Z. IGF-I slightly improves nuclear maturation and cleavage rate of bovine oocytes exposed to acute heat shock in vitro. Zygote, 2014. Disponível em: <http://dx.doi.org.ez93.periodicos.capes.gov.br/10.101 7/S096719941400015X>. Acessado em: 20 jul. 2014.

MERMILLOD, P.; DALBIE`S-TRAN, R.; UZBEKOVA, S. et al. Factors affecting oocyte quality: Who is driving the follicle? Reprod. Dom. Anim., v.43, p.393-400, 2008.

MÜLLER, K.; ELLENBERGER, C.; SHOON, H-A. Histomorphological and immunohistochemical study of angiogenesis and angiogenic factors in the ovary of the mare. Res. Vet. Sci., v.92, p.471-477, 2009.

OBERLENDER, G.; MURGAS, L.D.S.; ZANGERONIMO, M.G. et al. Role of insulin-like growth fator-I and follicular fluid from ovarian follicles with different diameters on porcine oocyte maturation and fertilization in vitro. Theriogenology, v.80, p.319-327, 2013.

OLIVEIRA, K.; MACHADO, M.A.; TONIOLLO, G.H. Avaliação do fator de crescimento IGF-I na maturação in vitro de oócitos caninos no meio TCM 199. Ciênc. Anim. Bras., v.10, p.560-567, 2009.
ORTEGA, H.H.; SALVETTI, N.R.; AMABLE, P. et al. Intraovarian localization of growth factors in induced cystic ovaries in rats. Anat. Histol. Embryol., v.36, p.94-102, 2007.

ORTEGA, H.H.; PALOMAR, M.M.; ACOSTA, J.C. et al. Insulin-like growth factor I in sera, ovarian follicles and follicular fluid of cows with spontaneous or induced cystic ovarian disease. Res. Vet. Sci., v.84, p.419-427, 2008.

PEREIRA, G.R.; LORENZO, P.L.; CARNEIRO, G.F. et al. Influence of equine growth hormone, insulin-like growth fator-1 and its interaction with gonadotropins on in vitro maturation and cytoskeleton morphology in equine oocytes. Animal, v.7, p.1493-1499, 2013.

PLENDL, J. Angiogenesis and vascular regression in the ovary. Anat. Histol. Embryol., v.29, p.257-266, 2000.

RAJKOVIC, A.; PANGAS, S.A.; MATZUK, M.M. Follicular development: mouse, sheep, and human models. In: NEILL, J.D. (Ed) Knobil and Neill's physiology of reproduction. 3.ed. Sant Louis: Elsevier, 2006. p.383-423.

REDMER, D.A.; REYNOLDS, L.P. Angiogenesis in the ovary. Rev. Reprod., v.1, p.182-192, 1996.

REYNAUD, K.; CHASTANT-MAILLARD, S.; BATARD, S. et al. IGF system and ovarian folliculogenesis in dog breeds of various sizes: is there a link? J. Endocrinol., v.206, p.85-92, 2010.

RODRIGUES, B.A.; RODRIGUES J.L. Meiotic response of in vitro matured canine oocytes under diferente proteins and heterologous hormone supplementation. Reprod. Domest. Anim., v.38, p.5862, 2003.

SATRAPA, R.A.; CASTILHO, A.S.; RAZZA, E.M. et al. Differential expression of members of the IGF system in OPU-derived oocytes from Nelore (Bos indicus) and Holstein (Bos taurus) cows. Anim. Reprod. Sci., v.138, p.155-158, 2013.

SHIMIZU, T.; KAWAHARA, M.; ABE, Y. et al. Follicular microvasculature and angiogenic factors in the ovaries of domestic animals. J. Reprod. Devel., v.49, p.181-192, 2003.

SHIN, S-Y.; LEE, H-J.; KO, D-S. et al. The regulators of VEGF expression in mouse ovaries. Yonsei Med. J., v.46, p.679-686, 2005.

SONGSASEN, N.; FICKES, A.; PUKAZHENTHI, B.S. et al. Follicular morphology, oocyte diameter and localization of fibroblast growth factors in the domestic dog ovary. Reprod. Dom. Anim., v.44, p.6570, 2009. 
STOUFFER, R.L. Structure, function, and regulation of the corpus luteum. In: NEILL, J.D. (Ed) Knobil and Neill's physiology of reproduction. 3.ed. Sant Louis: Elsevier, 2006. p.475-526.

VALLE, G.R.; FÓSCOLO, C.B. Falhas reprodutivas e seu tratamento em cães - relato de casos. Clínica Vet. (São Paulo), v.99, p.34-48, 2012.
VELAZQUEZ, M.A.; SPICER, L.J.; WATHES, D.C. The role of endocrine insulin-like growth factor-I (IGF-I) in female bovine reproduction. Domest. Anim. Endocrinol., v.35, p.325-342, 2008.

VENDOLA, K.; ZHOU, J.; WANG J. et al. Androgens promote oocyte insulin-like growth factor I expression and initiation of follicle development in the primate ovary. Biol. Reprod., v.61, p.353-357, 1999. 